\title{
Formic and acetic acids in a nitrogen matrix: Enhanced stability of the higher-energy conformer
}

\author{
Susy Lopes, ${ }^{1}$ Alexandra V. Domanskaya, ${ }^{2}$ Rui Fausto, ${ }^{1, a)}$ Markku Räsänen, ${ }^{2}$ and \\ Leonid Khriachtchev ${ }^{2, a)}$ \\ ${ }^{1}$ Department of Chemistry, University of Coimbra, Rua Larga, P-3004-535 Coimbra, Portugal \\ ${ }^{2}$ Department of Chemistry, University of Helsinki, P.O. Box 55, FIN-00014 Helsinki, Finland
}

(Received 1 July 2010; accepted 10 August 2010; published online 12 October 2010)

\begin{abstract}
Formic acid (HCOOH, FA) and acetic acid $\left(\mathrm{CH}_{3} \mathrm{COOH}, \mathrm{AA}\right)$ are studied in a nitrogen matrix. The infrared (IR) spectra of cis and trans conformers of these carboxylic acids (and also of the HCOOD isotopologue of FA) are reported and analyzed. The higher-energy cis conformer of these molecules is produced by narrowband near-IR excitation of the more stable trans conformer, and the cis-to-trans tunneling decay is evaluated spectroscopically. The tunneling process in both molecules is found to be substantially slower in a nitrogen matrix than in rare-gas matrices, the cis-form decay constants being approximately 55 and 600 times smaller in a nitrogen matrix than in an argon matrix, for FA and AA respectively. The stabilization of the higher-energy cis conformer is discussed in terms of specific interactions with nitrogen molecule binding with the $\mathrm{OH}$ group of the carboxylic acid. This model is in agreement with the observed differences in the IR spectra in nitrogen and argon matrices, in particular, the relative frequencies of the $\nu \mathrm{OH}$ and $\tau \mathrm{COH}$ modes and the relative intensities of the $\nu \mathrm{OH}$ and $\nu \mathrm{C}=\mathrm{O}$ bands. (C) 2010 American Institute of Physics.
\end{abstract}

[doi:10.1063/1.3484943]

\section{INTRODUCTION}

Formic acid $(\mathrm{HCOOH}, \mathrm{FA})$ and acetic acid $\left(\mathrm{CH}_{3} \mathrm{COOH}\right.$, AA) are simple carboxylic acids both identified in the interstellar medium. ${ }^{1,2}$ Carboxylic acids have biological value and provide an insight into prebiotic organic chemistry in the protoplanetary nebula. ${ }^{3}$ Acetic acid is of particular importance due to its structural proximity to glycine, the simplest amino acid. Formation of acetic acid was detected upon irradiation of binary mixtures of methane $\left(\mathrm{CH}_{4}\right)$ and carbon dioxide $\left(\mathrm{CO}_{2}\right)$ ices by energetic electrons at $12 \mathrm{~K}^{4}$ Electron bombardment mimics the energy transfer processes that occur in the track of the trajectories of $\mathrm{MeV}$ cosmic-ray particles.

Organic acids in the gas phase can partition into aerosol particles ${ }^{5}$ with the aid of foreign nuclei, such as alkaline mineral particles and elemental carbon, and by condensation and co-condensation with $\mathrm{NH}_{3}$. It is hypothesized that organic acids are at least one of the primary sources of $\mathrm{CCN}$ in the atmosphere, especially over the continental forested areas, due to their ubiquitous presence in the troposphere. ${ }^{6}$

FA and AA have two conformers (cis and trans), which differ by the orientation of the $\mathrm{OH}$ group (Fig. 1). They are good model systems for fundamental studies of conformational changes and intramolecular energy redistribution. The cis form is higher in energy than the trans form by approximately $1365 \mathrm{~cm}^{-1}$ for FA (gas-phase experimental data), ${ }^{7}$ and approximately $1880 \mathrm{~cm}^{-1}$ for AA (theoretical value). ${ }^{8}$ The calculated trans-to-cis conversion barriers are

\footnotetext{
${ }^{a)}$ Authors to whom correspondence should be addressed. Electronic addresses: rfausto@ci.uc.pt and leonid.khriachtchev@helsinki.fi.
}

$44 \mathrm{~kJ} \mathrm{~mol}^{-1}$ (3921 $\left.\mathrm{cm}^{-1}\right)$ (Ref. 9) and $49 \mathrm{~kJ} \mathrm{~mol}^{-1}$ $\left(4400 \mathrm{~cm}^{-1}\right)$ (Ref. 8) for FA and AA, respectively. Detailed infrared (IR) spectroscopic data for trans and cis conformers of these acids and their isotopomers have been reported in rare-gas matrices. ${ }^{10-14}$

The cis form of carboxylic acids can be obtained by vibrational excitation of the trans form. ${ }^{10,13,15}$ Once obtained, the higher-energy cis conformer converts back to the groundstate trans form. At low temperatures, quantum tunneling dominates the overbarrier reactions. Hydrogen tunneling in FA and AA has been the subject of several studies. ${ }^{9} 15-19$

cis- $\mathrm{CH}_{3} \mathrm{COOH}$ has a shorter lifetime in rare-gas matrices than cis- $\mathrm{HCOOH}$ [approximately $50 \mathrm{~s}$ (Ref. 18) versus $8 \mathrm{~min}$ (Ref. 16) in solid argon at $8 \mathrm{~K}$ ]. Deuteration of the $\mathrm{OH}$ group influences greatly the tunneling process, slowing it down by about four orders of magnitude. The conversion process of cis- $\mathrm{CH}_{3} \mathrm{COOD}$ and cis-HCOOD to the trans forms in an argon matrix at $8 \mathrm{~K}$ takes about 15 days. ${ }^{18,19}$ On the other hand, the tunneling rates in formic ${ }^{16}$ and acetic acids ${ }^{18}$ increase upon deuteration of $\mathrm{CH}$ or $\mathrm{CH}_{3}$ groups. This secondary isotopic effect is very interesting but lacks an explanation.

The tunneling rates in these species are strongly dependent on the matrix material. The cis- $\mathrm{HCOOH}$ decay rates change with the matrix polarizability as $k_{\mathrm{Xe}}<k_{\mathrm{Kr}}<k_{\mathrm{Ar}}$ $<k_{\mathrm{Ne}} \cdot{ }^{15,16}$ However, the decay of cis-HCOOD follows almost the opposite trend: $k_{\mathrm{Xe}} \approx k_{\mathrm{Kr}}>k_{\mathrm{Ar}} \approx k_{\mathrm{Ne}}{ }^{19}$ With respect to the reaction barrier height, which increases in more polarizable hosts, the order of the rate constants in HCOOD is anomalous. ${ }^{15,16}$ Similar "anomalous" behavior was also reported for $\mathrm{AA}\left(k_{\mathrm{Xe}}>k_{\mathrm{Ar}} \geq k_{\mathrm{Kr}}\right) .{ }^{18}$ Clearly, in addition to the 


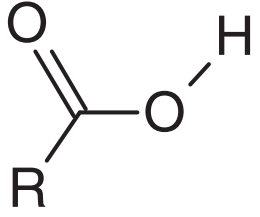

trans

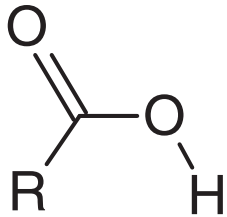

cis
FIG. 1. Trans (most stable) and cis (higher energy) conformers of formic acid $(\mathrm{R}=\mathrm{H})$ and acetic acid $\left(\mathrm{R}=\mathrm{CH}_{3}\right)$.

barrier change upon solvation in polarizable media, other factors can also influence the cis-to-trans conversion. ${ }^{15,16,19}$

Some experimental results suggest that the cis conformers might be stabilized in media resembling interstellar and atmospheric environments. An experimental study of AA and FA aerosol nanoparticles generated at $78 \mathrm{~K}$ and investigated using in situ rapid-scan Fourier transform infrared spectroscopy (FTIR) shows that the spectra of the particles have the same characteristic splitting of the $\nu(\mathrm{C}=\mathrm{O}), \delta(\mathrm{CH})$, and $\nu(\mathrm{C}-\mathrm{O})$ bands as the crystalline bulk. ${ }^{20}$ One possible explanation for the observed splitting is the co-existence of the trans and cis conformations in the chains, which would presumably destroy the planarity of the chains; however, the polymorphism of molecular chains made from trans subunits cannot be excluded. Crystalline acetic acid shows similar spectral splitting which might also be attributed to the inclusion of cis-oriented subunits. ${ }^{21}$

The tentative observation of the cis conformation in hydrogen-bonded systems agrees well with the general idea that complexation, dimerization, or solvation of higherenergy conformers can significantly decelerate or even stop the tunneling decay process. ${ }^{15,22}$ For example, the cis- $\mathrm{HCOOH} \cdots \mathrm{H}_{2} \mathrm{O}$ complex is stable at $9 \mathrm{~K}$ on a day scale. The lifetime of cis-FA in this complex might be practically infinite at low temperatures, i.e., tunneling to the trans conformer is efficiently suppressed. ${ }^{15}$ Studies of the interaction of carboxylic acids with nitrogen might lead to a better understanding of the role of conformational isomerism in dark interstellar clouds ${ }^{23}$ and the Earth's atmosphere.

In the present work, we report new results on spectroscopy of formic and acetic acids in a nitrogen matrix and on the stabilization of higher-energy cis conformers in this medium. The stabilization effect is discussed in terms of specific interactions between the matrix and embedded molecules.

\section{COMPUTATIONAL DETAILS AND RESULTS}

The quantum chemical calculations were performed using GAMESS, version R1 (24-Mar-2007) (Ref. 24) at the MP2 level of theory ${ }^{25}$ using the $6-311++\mathrm{G}(2 \mathrm{~d}, 2 \mathrm{p})$ basis set. ${ }^{26,27}$ This basis set has been shown to reproduce the experimental structural and vibrational properties of FA with an acceptable accuracy. ${ }^{11,28,29}$ The optimization criteria parameter OPTTOL was set to 0.00001 hartree/bohr. This parameter corresponds to the maximum value allowed to the energy gradient and also controls the maximum allowed value of the root mean square gradient, which is given by $1 / 3$ of OPT-
TOL. The optimized structures of all FA $\cdots \mathrm{N}_{2}$ and AA $\cdots \mathrm{N}_{2}$ complexes were confirmed to correspond to the true energy minima on the potential energy surfaces by inspection of the Hessian matrices. The vibrational spectra were computed at the same level of theory. The calculated MP2 / 6-311++G(2d,2p) vibrational frequencies and intensities of the fundamental modes for the cis and trans forms of $\mathrm{HCOOH}, \mathrm{HCOOD}$, and $\mathrm{CH}_{3} \mathrm{COOH}$ are listed together with the assignments of the observed fundamental transitions (Tables I and II). The calculated spectra of FA and AA are shown in Figs. 2 and 3 (lower traces).

The most stable complex has the $\mathrm{N}_{2}$ molecule interacting with the $\mathrm{OH}$ bond of the carboxylic acid (Fig. 4). This result is in agreement with the previous study on the trans-FA $\cdots \mathrm{N}_{2}$ system. ${ }^{28}$ All optimized complexes are presented in Figs. S1-S4. ${ }^{30}$ Most of the trans-FA $\cdots \mathrm{N}_{2}$ structures (Fig. S2) were not found previously by Lundell et $a l^{28}$

The interaction energies of the FA $\cdots \mathrm{N}_{2}$ and AA $\cdots \mathrm{N}_{2}$ complexes were evaluated (see Fig. 4). For the trans species, the interaction energy of approximately $-4.0 \mathrm{~kJ} \mathrm{~mol}^{-1}$ (zero point and basis set superposition error corrected energy) was obtained for both FA and AA. This value agrees fairly with the interaction energy reported by Lundell et al. ${ }^{28}$ for the trans-FA $\cdots \mathrm{N}_{2}$ complex ( -5.3 to $-6.2 \mathrm{~kJ} \mathrm{~mol}^{-1}$ depending on the basis set). The interaction is slightly stronger in the complexes of the cis conformers. The calculations reveal a stronger stabilization for AA than for FA $\left(-5.1 \mathrm{~kJ} \mathrm{~mol}^{-1}\right.$ in AA versus $-4.4 \mathrm{~kJ} \mathrm{~mol}^{-1}$ in FA; Fig. 4).

The calculated characteristic vibrational frequencies and intensities for the strongest complexes are compared with the data for the monomers in Table III. According to the calculations, the $\mathrm{OH}$ stretching frequency decreases by approximately 20 to $30 \mathrm{~cm}^{-1}$ and substantially intensifies (three to four times) for both acids in both conformational states. The $\mathrm{OH}$ torsional mode shows blue shifts (approximately 60 to $80 \mathrm{~cm}^{-1}$ ) and its intensity slightly decreases upon complexation except for the trans-AA $\cdots \mathrm{N}_{2}$ complexes. The $\nu \mathrm{C}=\mathrm{O}$ mode red-shifts by ca. $5 \mathrm{~cm}^{-1}$ and slightly gains intensity for the cis conformers, whereas the intensity slightly decreases for the trans forms. The changes of both frequency and intensity upon complexation of FA and AA are in agreement with the expectations for an $\mathrm{H}$-bond type interaction. ${ }^{31-34}$ The spectral data for other complexes are presented in Table S-I. ${ }^{30}$

\section{A. Experimental details and results}

Gaseous mixtures of FA ( $\mathrm{HCOOH}$, Kebo Lab, 99\%) and AA $\left(\mathrm{CH}_{3} \mathrm{COOH}\right.$, Kebo Lab, 99\%) with nitrogen (AGA/ Linde 6.0) were prepared with a typical ratio of 1:1200. The acids were purified by a few freezing-pumping cycles. Nitrogen was used as supplied. The mixtures were deposited onto a CsI window at $8.5 \mathrm{~K}$ in a close-cycle helium cryostat (APD, DE 202A). The spectra were recorded with a Nicolet 60SX FTIR instrument by coadding 200 interferograms with $1 \mathrm{~cm}^{-1}$ spectral resolution. HCOOD molecules were pro- 
TABLE I. Assignment of the spectra of the trans and cis forms of HCOOH and HCOOD isolated in argon and nitrogen matrices. The calculated fundamental frequencies (in $\mathrm{cm}^{-1}$ ) and intensities (in $\mathrm{km} \mathrm{mol}^{-1}$, in parenthesis) for trans and cis conformers of $\mathrm{HCOOH}$ and HCOOD were obtained at the $\mathrm{MP} 2 / 6-311++\mathrm{G}(2 \mathrm{~d}, 2 \mathrm{p})$ level of theory. Frequencies in italic indicate tentative assignments.

\begin{tabular}{|c|c|c|c|c|c|c|}
\hline \multirow[b]{2}{*}{ Assignment } & \multicolumn{2}{|c|}{$\mathrm{N}_{2}$ matrix } & \multicolumn{2}{|c|}{ Ar matrix ${ }^{a}$} & \multicolumn{2}{|c|}{ Calc. } \\
\hline & trans & cis & trans & cis & trans & cis \\
\hline \multicolumn{7}{|l|}{$\mathrm{HCOOH}$} \\
\hline$\nu \mathrm{OH}$ & 3528.2 & 3598.1 & 3549 & 3617 & $3777.9(81.8)$ & $3844.5(81.6)$ \\
\hline$\nu \mathrm{CH}$ & 2967.5 & 2900.6 & 2955 & 2898 & $3127.2(33.6)$ & $3039.4(64.8)$ \\
\hline$\nu \mathrm{C}=\mathrm{O}$ & 1762.2 & 1803.0 & 1768 & 1808 & $1784.2(334.3)$ & $1824.4(268.3)$ \\
\hline$\gamma \mathrm{CH}$ & $1342 \mathrm{w}$ & $1391 \mathrm{w}$ & 1383 & 1392 & $1424.4(1.5)$ & $1439.3(0.1)$ \\
\hline $\mathrm{CO}-\mathrm{COH}$ def. & $1265 \mathrm{w}$ & 1275.9 & 1215 & 1246 & $1314.3(9.0)$ & $1285.5(294.4)$ \\
\hline $\mathrm{COH}-\mathrm{CO}$ def. & 1119.4 & $\sim 1120$ & 1103 & 1106 & $1119.9(284.2)$ & 1109.4(81.6) \\
\hline wCH & 1040.5 & 1047.0 & 1038 & $\cdots$ & $1060.8(3.8)$ & $1038.8(0.2)$ \\
\hline$\tau \mathrm{COH}$ & 672.3 & 536.2 & 635 & 504 & $674.7(143.5)$ & $535.2(88.1)$ \\
\hline$\delta \mathrm{OCO}$ & 637.0 & 667.8 & 629 & 662 & $629.9(39.1)$ & 659.1(11.7) \\
\hline \multicolumn{7}{|l|}{ HCOOD } \\
\hline$\nu \mathrm{OD}$ & 2602.5 & 2657.4 & 2619.5 & 2668.7 & $3127.7(30.0)$ & $3039.3(63.1)$ \\
\hline$\nu \mathrm{CH}$ & 2973.7 & 2899.4 & 2961.2 & 2895.3 & $1777.5(317.7)$ & $1816.8(297.1)$ \\
\hline$\nu \mathrm{C}=\mathrm{O}$ & 1749.6 & 1790.6 & 1767.2 & 1799.3 & $1415.5(1.4)$ & $1437.9(0.6)$ \\
\hline$\gamma \mathrm{CH}$ & $\cdots$ & $\ldots$ & 1374.3 & 1395.4 & $1191.7(179.6)$ & $1172.6(303.2)$ \\
\hline$\nu \mathrm{C}-\mathrm{O}$ & 1187.9 & 1176.8 & 1181.7 & 1164.0 & $1058.2(1.3)$ & $1038.8(0.1)$ \\
\hline wCH & 1038.2 & $\cdots$ & 1036.4 & 1041.0 & $1000.1(85.0)$ & $925.7(2.9)$ \\
\hline$\delta \mathrm{COD}$ & 989.8 & 929.5 & 971.0 & 910.5 & $564.6(40.1)$ & $631.9(12.1)$ \\
\hline $\mathrm{OCO}-\mathrm{COD}$ def. & 571.3 & 641.2 & 559.7 & 633.6 & $530.2(88.7)$ & $402.5(33.1)$ \\
\hline$\tau \mathrm{COD}$ & 528.9 & $\cdots$ & 506.7 & $\cdots$ & $3127.7(30.0)$ & $3039.3(63.1)$ \\
\hline
\end{tabular}

${ }^{\mathrm{a}}$ From Refs. 11 and 19 (averaged value of two sites).

duced by an H/D exchange with deuterated surfaces in the deposition line. The obtained deuteration degree $(\sim 15 \%)$ was sufficient to observe and assign the main fundamental frequencies.
The trans-to-cis conversion was promoted by selective vibrational excitation by using an optical parametric oscillator with IR extension [Sunlite Continuum, full width at half maximum $(\mathrm{FWHM}) \sim 0.1 \mathrm{~cm}^{-1}$. cis-AA was produced by

TABLE II. Assignment of the spectra of the trans and cis forms of $\mathrm{CH}_{3} \mathrm{COOH}$ isolated in argon and nitrogen matrices. The calculated fundamental frequencies (in $\mathrm{cm}^{-1}$ ) and intensities (in $\mathrm{km} \mathrm{mol}^{-1}$, in parenthesis) for trans and cis conformers of $\mathrm{CH}_{3} \mathrm{COOH}$ were obtained at the $\mathrm{MP} 2 / 6-311++\mathrm{G}(2 \mathrm{~d}, 2 \mathrm{p})$ level of theory. Frequencies in italic indicate tentative assignments.

\begin{tabular}{|c|c|c|c|c|c|c|c|}
\hline \multirow[b]{2}{*}{ Assignment } & \multicolumn{3}{|c|}{$\mathrm{CH}_{3} \mathrm{COOH}\left(\mathrm{N}_{2}\right)$} & \multicolumn{2}{|c|}{$\mathrm{CH}_{3} \mathrm{COOH}(\mathrm{Ar})^{\mathrm{a}}$} & \multicolumn{2}{|c|}{ Calc. } \\
\hline & Site I & Site II & cis & trans & cis & trans & cis \\
\hline$\nu \mathrm{OH}$ & 3544.1 & 3551.9 & 3610.7 & 3563.8 & 3622.6 & $3787.3(77.5)$ & $3852.9(63.3)$ \\
\hline$\nu \mathrm{HCH}_{2} \mathrm{~s}$ & 3035.8 & 3035.8 & $\cdots$ & 3051 & $\cdots$ & $3228.7(2.6)$ & $3221.6(1.9)$ \\
\hline$\nu \mathrm{HCH}_{2}$ a & 3002.4 & 2995.6 & 2990.0 & 2996 & $\cdots$ & $3187.8(1.8)$ & $3169.8(3.8)$ \\
\hline$\nu \mathrm{CH}_{3}$ & 2965.4 & $\begin{array}{l}2954.0 \\
2947.4\end{array}$ & 2942.3 & 2944 & $\cdots$ & $3107.6(1.2)$ & $3091.7(3.5)$ \\
\hline$\nu \mathrm{C}=\mathrm{O}$ & 1775.1 & 1777.6 & 1797.2 & 1779.0 & 1807.4 & $1801.0(290.3)$ & $1828.1(247.4)$ \\
\hline$\delta \mathrm{HCH}_{2} \mathrm{a}$ & 1445.5 & 1441.0 & 1445.7 & 1438.8 & 1448.3 & $1505.4(8.4)$ & $1513.2(7.8)$ \\
\hline$\delta \mathrm{HCH}_{2} \mathrm{~s}$ & 1435.7 & 1435.7 & 1438.8 & 1433.6 & 1444.5 & $1500.3(16.2)$ & $1500.5(7.4)$ \\
\hline$\delta \mathrm{CH}_{3}$ & 1387.6 & 1385.7 & 1371.91370 .2 & 1379.41324 .4 & 1368.3 & $1432.7(48.9)$ & $1420.4(44.3)$ \\
\hline $\mathrm{CO}-\mathrm{COH}$ def. & 1275.9 & 1280.5 & 1234.01210 .4 & 1259.4 & 1192.9 & $1350.3(39.0)$ & $1215.0(7.6)$ \\
\hline $\mathrm{COH}-\mathrm{CO}$ def. & 1205.91183 .9 & 1196.51177 .4 & $1301.71290 .5^{\mathrm{b}}$ & 1179.8 & $1285.41271 .9^{\mathrm{b}}$ & $1208.1(212.8)$ & $1306.3(373.5)$ \\
\hline$\gamma \mathrm{CH}_{3}$ a & 1048.1 & $\cdots$ & 1044.1 & 1047.2 & 1042.4 & $1082.7(5.1)$ & $1076.8(3.3)$ \\
\hline$\gamma \mathrm{CH}_{3} \mathrm{~s}$ & 990.9 & $\cdots$ & $\cdots$ & 985.5 & 982.2 & 1009.4(82.4) & 1000.4(11.9) \\
\hline$\nu \mathrm{C}-\mathrm{C}$ & 856.3 & $\cdots$ & 857.4 & $\cdots$ & 848.6 & $867.8(7.9)$ & $860.6(40.5)$ \\
\hline$\tau \mathrm{COH}$ & 663.2 & 656.1 & 489.3 & 637.8 & 458.0 & $661.0(90.3)$ & 465.1(101.3) \\
\hline$\delta \mathrm{OCO}$ & 588.3 & 585.7 & 600.6 & 580.4 & $\cdots$ & $584.6(36.3)$ & $602.3(1.4)$ \\
\hline$\gamma \mathrm{C}=\mathrm{O}$ & 554.2546 .4 & 556.0549 .4 & $\cdots$ & 534.2 & $\cdots$ & $550.7(30.9)$ & $598.6(7.4)$ \\
\hline$\delta \mathrm{CC}=\mathrm{O}$ & 430.2 & $\cdots$ & $\cdots$ & 428 & $\cdots$ & $425.4(4.1)$ & $434.4(3.7)$ \\
\hline$\tau \mathrm{CH}_{3}$ & $\cdots$ & $\cdots$ & $\cdots$ & $\cdots$ & $\cdots$ & $75.4(0.2)$ & $92.2(1.2)$ \\
\hline
\end{tabular}

\footnotetext{
${ }^{\mathrm{a}}$ Reference 14 .
} 

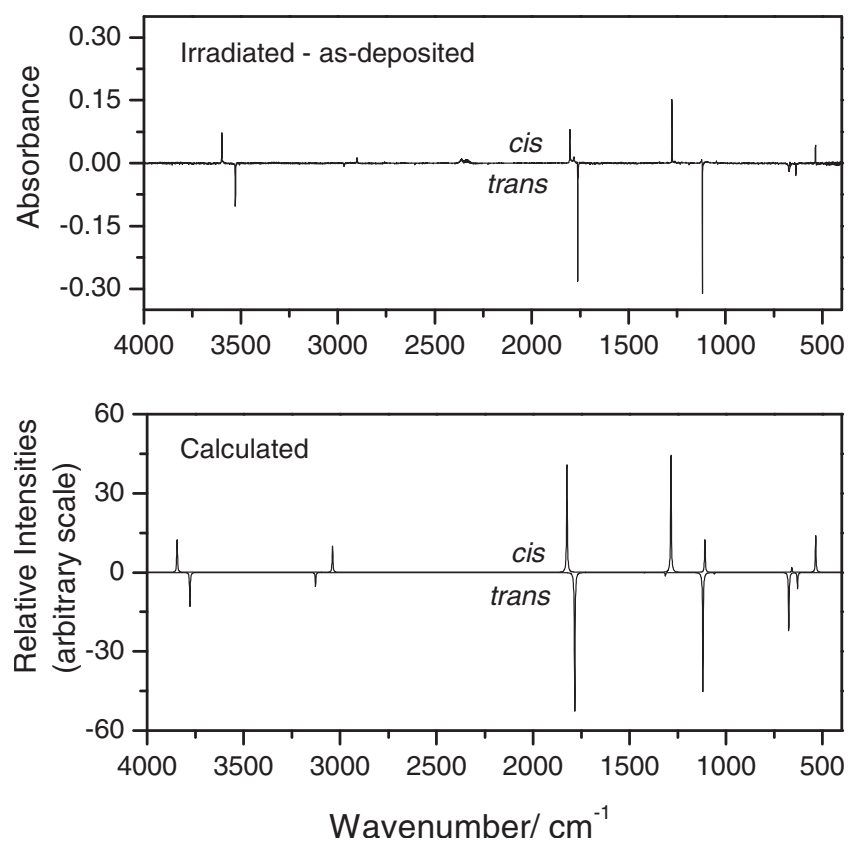

FIG. 2. Top: FTIR difference spectrum of FA in solid $\mathrm{N}_{2}$. Result of irradiation at $5288 \mathrm{~cm}^{-1}$ showing conversion of trans-FA into cis-FA. Bottom: MP2/6-311++G(2d,2p) calculated infrared spectra of trans-FA (downward peaks) and cis-FA (upward peaks). In the calculated spectra, bands were represented by Lorentzian functions centered at the calculated wavenumbers and with FWHM (full width at half maximum) equal to $4 \mathrm{~cm}^{-1}$.

exciting the $\nu \mathrm{OH}+\delta \mathrm{COH}$ combination mode of trans-AA at $4724.5 \mathrm{~cm}^{-1}$. cis-FA was prepared by exciting the $\nu \mathrm{OH}$ $+\nu \mathrm{C}=\mathrm{O}$ combination mode of trans-FA at $5288 \mathrm{~cm}^{-1}$. The cis-HCOOD was produced by the IR light source of the spectrometer (Globar).
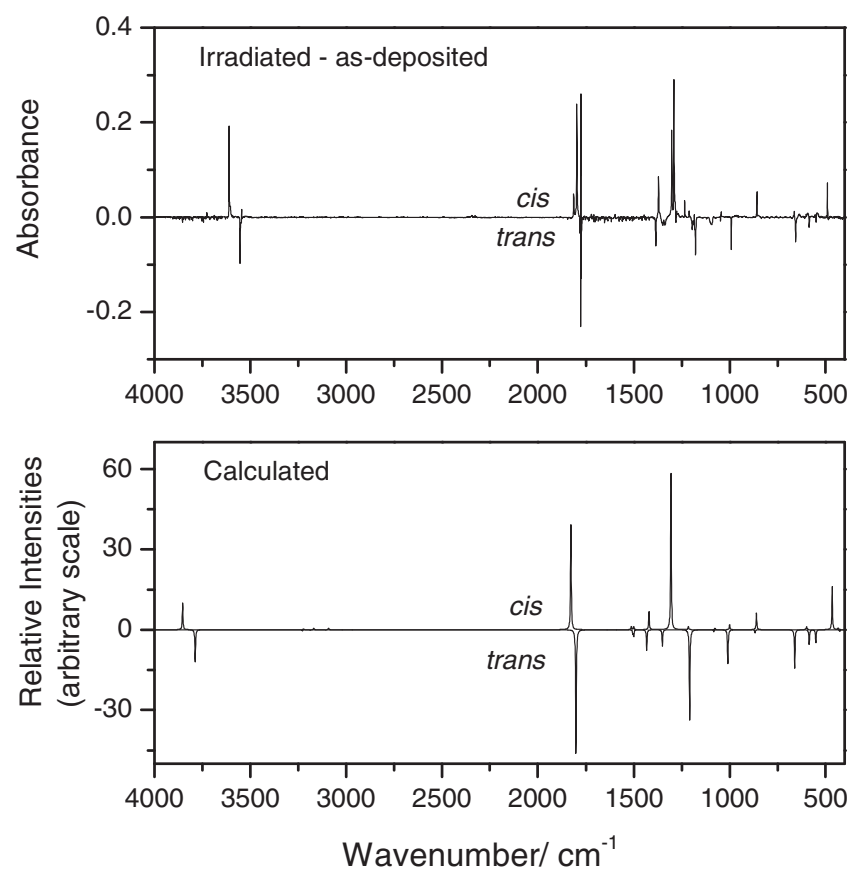

FIG. 3. Top: FTIR difference spectrum of AA in solid $\mathrm{N}_{2}$. Result of irradiation at $4724.5 \mathrm{~cm}^{-1}$ showing conversion of trans-AA into cis-AA. Bottom: MP2 $/ 6-311++G(2 d, 2 p)$ calculated infrared spectra of trans-AA (downward peaks) and cis-AA (upward peaks). In the calculated spectra, bands were represented by Lorentzian functions centered at the calculated wavenumbers and with FWHM equal to $4 \mathrm{~cm}^{-1}$.

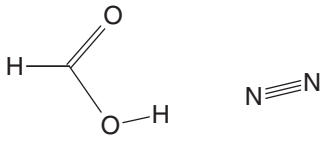

trans- $\mathrm{HCOOH}^{\cdots} \mathrm{N}_{2}\left(-4.1 \mathrm{~kJ} \mathrm{~mol}^{-1}\right)$<smiles>O=CO</smiles><smiles>N#N</smiles>

cis- $\mathrm{HCOOH} \cdots \mathrm{N}_{2}\left(-4.4 \mathrm{~kJ} \mathrm{~mol}^{-1}\right)$<smiles>O=CC(=O)O</smiles><smiles>C1=NCC1</smiles>

trans $-\mathrm{CH}_{3} \mathrm{COOH} \cdots \mathrm{N}_{2}\left(-4.2 \mathrm{~kJ} \mathrm{~mol}^{-1}\right)$<smiles>CC(=O)O</smiles><smiles>N=N</smiles>

cis- $\mathrm{CH}_{3} \mathrm{COOH} \cdots \mathrm{N}_{2}\left(-5.1 \mathrm{~kJ} \mathrm{~mol}^{-1}\right)$
FIG. 4. Schematic structures of the strongest complexes of formic and acetic acids in cis and trans forms with molecular nitrogen at the MP2/6-311 $++\mathrm{G}(2 \mathrm{~d}, 2 \mathrm{p})$ level of theory. The interaction energies of the complexes are given in parenthesis and correspond to zero point and basis set superposition error (BSSE) corrected values. The calculated BSSE for cis and trans complexes amount to -2.6 and $-2.3 \mathrm{~kJ} \mathrm{~mol}^{-1}$, respectively. Optimized structures for the complexes are provided in Figs. S1-S4 (supplementary material). Calculated $\mathrm{N} \cdots \mathrm{H}$ distances are $2.199,2.209,2.218$, and $2.223 \AA$ for trans $-\mathrm{HCOOH} \cdots \mathrm{N}_{2}, \quad$ cis- $\mathrm{HCOOH} \cdots \mathrm{N}_{2}$, trans $-\mathrm{CH}_{3} \mathrm{COOH} \cdots \mathrm{N}_{2}$, and cis- $\mathrm{CH}_{3} \mathrm{COOH} \cdots \mathrm{N}_{2}$, respectively.

In the kinetic measurements, the cis-conformer decay was monitored by measuring the intensity of the $\mathrm{CO}-\mathrm{COH}$ def. fundamental band of cis- $\mathrm{HCOOH}\left(1275.9 \mathrm{~cm}^{-1}\right)$ as a function of time. In the case of cis- $\mathrm{CH}_{3} \mathrm{COOH}$, the split $\mathrm{COH}-\mathrm{CO}$ def. band $\left(1301.7\right.$ and $\left.1290.5 \mathrm{~cm}^{-1}\right)$ and the $\delta \mathrm{CH}_{3}$ band $\left(1370.5 \mathrm{~cm}^{-1}\right)$ were used. A long-pass optical filter $\left(>1500 \mathrm{~cm}^{-1}\right)$ was inserted between the sample and the Globar source in order to suppress high frequency light components which could accelerate the cis-to-trans conversion process. The Globar light was blocked between the measurements. The OD form of cis-FA is very stable over time due to the well-known mass effect on the tunneling rate $^{12,15-19}$ and its decay was not studied here.

The spectra of FA and AA in a nitrogen matrix at ca. 8.5 $\mathrm{K}$ are presented in Figs. 2 and 3. The results of vibrational excitation (at $5288 \mathrm{~cm}^{-1}$ for FA and at $4724.5 \mathrm{~cm}^{-1}$ for AA) are shown. The assignments of the observed fundamental transitions are given in Tables I and II, together with the calculated MP2/6-311++G(2d,2p) vibrational frequencies and intensities of the fundamental modes for the cis and trans forms of $\mathrm{HCOOH}, \mathrm{HCOOD}$, and $\mathrm{CH}_{3} \mathrm{COOH}$.

The cis-to-trans decay curves for FA and AA are shown in Figs. 5 and 6. The decay rates obtained in a nitrogen matrix at different temperatures are compared with the rates previously measured in an argon matrix ${ }^{16,18}$ in Fig. 7.

\section{DISCUSSION}

\section{A. Spectral assignment}

For both acids, the experimental IR spectra are reproduced well by theory, which allows a straightforward identification of the bands (Figs. 2 and 3). The assignments of the 
TABLE III. Calculated $\nu \mathrm{OH}, \nu \mathrm{C}=\mathrm{O}$ and $\tau \mathrm{COH}$ wavenumbers $\left(\nu\right.$ in $\left.\mathrm{cm}^{-1}\right)$ and infrared intensities $\left(I_{\mathrm{IR}}\right.$ in $\left.\mathrm{km} \mathrm{mol}^{-1}\right)$ for monomeric cis and trans forms of FA and AA and their most stable complexes with $\mathrm{N}_{2}$. (See Figs. 1-4.)

\begin{tabular}{|c|c|c|c|c|c|c|c|c|c|c|c|c|}
\hline & \multicolumn{2}{|c|}{$\nu \mathrm{OH}$} & \multicolumn{2}{|c|}{$\nu \mathrm{C}=\mathrm{O}$} & \multicolumn{2}{|c|}{$\tau \mathrm{COH}$} & \multicolumn{2}{|c|}{$\nu \mathrm{OH}$} & \multicolumn{2}{|c|}{$\nu \mathrm{C}=\mathrm{O}$} & \multicolumn{2}{|c|}{$\tau \mathrm{COH}$} \\
\hline & $\nu$ & $I_{\mathrm{IR}}$ & $\nu$ & $I_{\mathrm{IR}}$ & $\nu$ & $I_{\mathrm{IR}}$ & $\nu$ & $I_{\mathrm{IR}}$ & $\nu$ & $I_{\mathrm{IR}}$ & $\nu$ & $I_{\mathrm{IR}}$ \\
\hline & \multicolumn{2}{|c|}{ cis- $\mathrm{HCOOH}$} & \multicolumn{10}{|c|}{ trans $-\mathrm{HCOOH}$} \\
\hline Monomer & 3844.5 & 81.6 & 1824.4 & 268.3 & 535.2 & 88.1 & 3777.9 & 81.8 & 1784.2 & 334.3 & 674.7 & 143.5 \\
\hline Complex & 3820.3 & 292.3 & 1820.6 & 297.9 & 620.9 & 79.0 & 3747.6 & 282.1 & 1779.1 & 321.0 & 747.7 & 118.5 \\
\hline a & -24.2 & 3.6 & -3.8 & 1.1 & 85.7 & 0.9 & -30.3 & 3.4 & -5.1 & 0.96 & 73.0 & 0.8 \\
\hline & \multicolumn{2}{|c|}{ cis- $\mathrm{CH}_{3} \mathrm{COOH}$} & \multicolumn{10}{|c|}{ trans $-\mathrm{CH}_{3} \mathrm{COOH}$} \\
\hline Monomer & 3852.9 & 63.3 & 1828.1 & 247.4 & 465.1 & 101.3 & 3787.3 & 77.5 & 1801.0 & 290.3 & 661.0 & 90.3 \\
\hline Complex & 3833.6 & 233.1 & 1824.6 & 270.0 & 537.5 & 72.3 & 3762.6 & 266.8 & 1795.2 & 277.1 & 718.6 & 96.9 \\
\hline a & -19.3 & 3.7 & -3.5 & 1.1 & 72.4 & 0.7 & -24.7 & 3.4 & -5.8 & 0.95 & 57.6 & 1.1 \\
\hline
\end{tabular}

${ }^{\mathrm{a}}$ The values presented in this row correspond to frequency shifts $\left(\nu_{\text {complex }}-\nu_{\text {monomer }}\right)$ or intensity ratios $\left(\mathrm{I}_{\text {complex }} / \mathrm{I}_{\text {monomer }}\right)$.

observed fundamental transitions are given in Tables I and II, where they are compared with the experimental data obtained in an argon matrix. ${ }^{11,14,19}$

The assignments for trans- $\mathrm{HCOOH}$ are doubtless except for the low intensity $\mathrm{CO}-\mathrm{COH}$ def. and $\gamma \mathrm{CH}$ modes, which are tentatively assigned to the weak bands at 1265 and $1342 \mathrm{~cm}^{-1}$ in a nitrogen matrix $\left(1215\right.$ and $1383 \mathrm{~cm}^{-1}$ in an Ar matrix). ${ }^{11}$ For $c i s-\mathrm{HCOOH}, \gamma \mathrm{CH}$ is also predicted to have low intensity (see Table I), and it is tentatively ascribed to the band observed at $1391 \mathrm{~cm}^{-1}$, appearing at almost the same frequency as in an $\operatorname{Ar}$ matrix $\left(1392 \mathrm{~cm}^{-1}\right) .{ }^{11}$ The assignment of the $\mathrm{COH}-\mathrm{CO}$ def. mode of $c i s-\mathrm{HCOOH}$ is complicated by a fact that this vibration almost coincides with the analogous vibration of the trans conformer. The band of the cis form is hidden by the wing of the trans-FA band and even in the difference spectrum is not easy to be noticed. Nevertheless, the theory predicts this band to be intense (see Table I), so that there is no other possibility for assignment.

In the case of $\mathrm{HCOOD}$, the very weak $\gamma \mathrm{CH}$ and $\mathrm{wCH}$ modes (see Table I) could not be observed experimentally. The assignment of the OCO-COD def. mode of the cis form is uncertain also due to its low intensity.

The results for trans-AA indicate trapping into two main matrix sites (named I and II) in a nitrogen matrix. In our experiments, only molecules in site II were vibrationally ex-

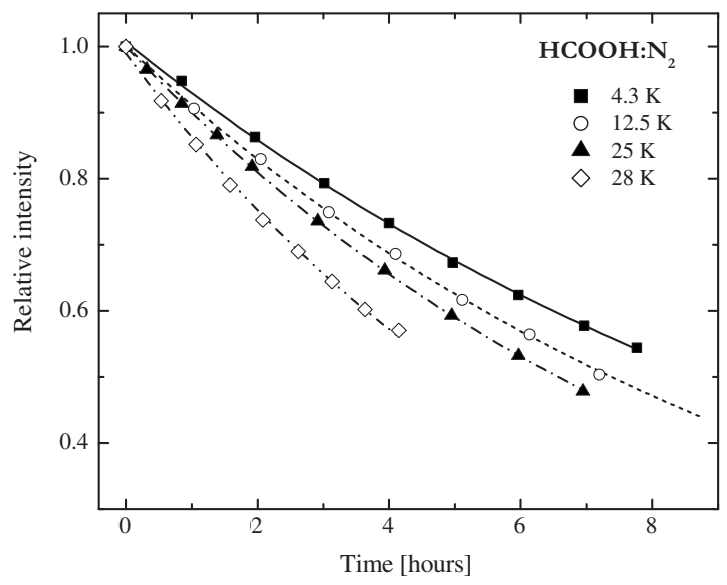

FIG. 5. Decay of cis-HCOOH in a nitrogen matrix at different temperatures. cited by IR radiation and consequently converted to the cis form.

\section{B. Interaction with nitrogen}

The potential energy surfaces of the FA $\cdots \mathrm{N}_{2}$ and AA $\cdots \mathrm{N}_{2}$ systems reveal that the $1: 1$ hydrogen-bonded complexes feature the most important interaction in a nitrogen matrix. If a specific interaction dominates one can consider the 1:1 complex surrounded by a matrix. For an Ar matrix, this approach is validated by calculations of FA $\cdots$ Ar complexes by Wawrzyniak et al. ${ }^{35,36}$ They found that the FA $\cdots$ Ar structures with an $\mathrm{Ar}$ atom bonded to the $\mathrm{OH}$ group of FA have substantially smaller interaction energies $(-1.5$ to $-2.0 \mathrm{~kJ} \mathrm{~mol}^{-1}$ ) than in the present case of similar nitrogen complexes. Thus, the substitution of the Ar atom by a nitrogen molecule is energetically favorable. If the $\mathrm{OH} \cdots \mathrm{N}_{2}$ interaction is dominant, the result of complexation will be accordingly reflected in the vibrational spectra. Adding additional $\mathrm{N}_{2}$ molecules to the $1: 1$ complexes to describe the matrix effect is computationally difficult and, in the present case, does not seem to be strictly required.

The data obtained in solid nitrogen can be compared with less perturbing hosts such as neon and argon matrices. ${ }^{11,14,22}$ The experimental observations in a nitrogen

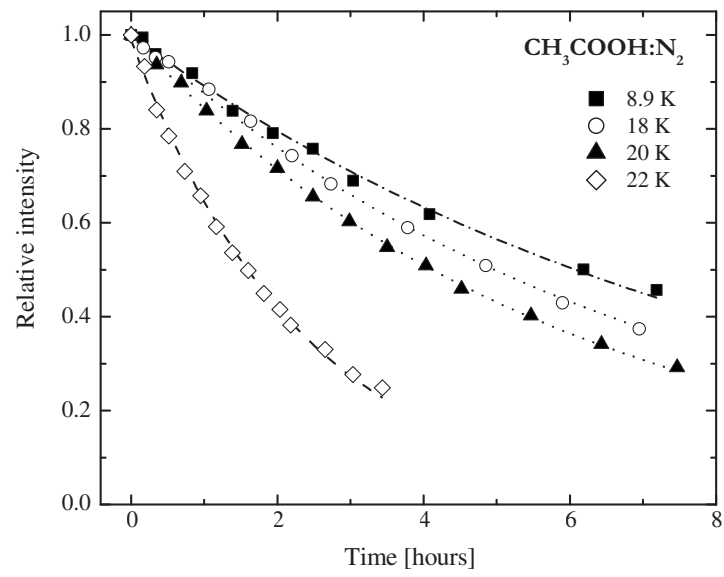

FIG. 6. Decay of $c i s-\mathrm{CH}_{3} \mathrm{COOH}$ in a nitrogen matrix at different temperatures. 


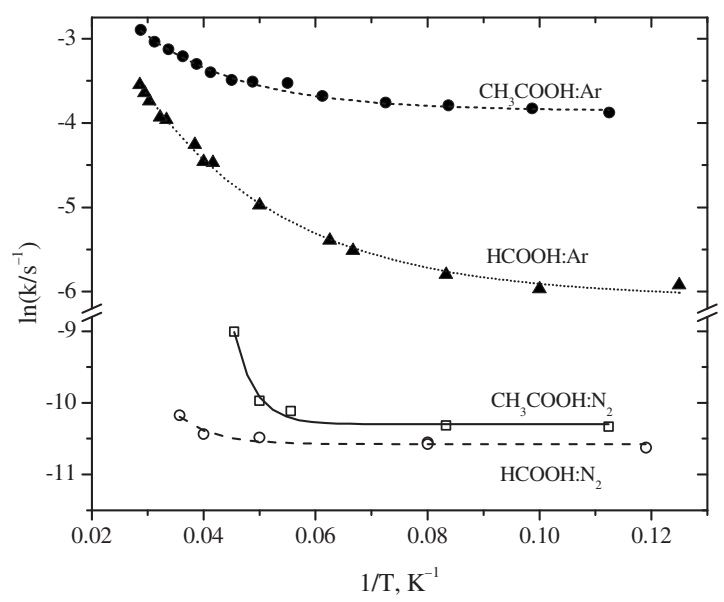

FIG. 7. Tunneling rate constants for cis- $\mathrm{HCOOH}$ and $c i s-\mathrm{CH}_{3} \mathrm{COOH}$ in nitrogen (this work) and argon (data from Refs. 16 and 18) matrices.

matrix agree with the spectral predictions for the strongest 1:1 complexes. The $\nu \mathrm{OH}$ frequency of FA decreases by 19 and $21 \mathrm{~cm}^{-1}$ for cis and trans forms, respectively, from the values in an argon matrix (Table IV) and by 39 and $41 \mathrm{~cm}^{-1}$ compared to a neon matrix. The $\tau \mathrm{COH}$ frequency increases by 32 (cis) and $37 \mathrm{~cm}^{-1}$ (trans) from values in an argon matrix and by 39 and $34 \mathrm{~cm}^{-1}$ compared to a Ne matrix. For AA, $\nu \mathrm{OH}$ shows red-shifts by $12 \mathrm{~cm}^{-1}$ (cis), $20 \mathrm{~cm}^{-1}$ (trans, site I), and $-12 \mathrm{~cm}^{-1}$ (trans, site II), and $\tau \mathrm{COH}$ shifts by $+31($ cis $),+25 \mathrm{~cm}^{-1}$, (trans, site I) and $12 \mathrm{~cm}^{-1}$ (trans, site II) compared to an Ar matrix. These trends are in agreement with the calculations for the strongest complexes (Table III). The 1:1 interaction with nitrogen produces larger redshifts compared to interaction with argon, as calculated for FA. ${ }^{35,36}$

Analysis of the experimental intensities leads to similar conclusions. We assume that the $\nu \mathrm{OH} / \nu \mathrm{C}=\mathrm{O}$ intensity ratio is a fingerprint of the $\mathrm{OH} \cdots \mathrm{N}_{2}$ interaction in a nitrogen matrix because the $\mathrm{C}=\mathrm{O}$ stretching intensity does not change much upon complexation. For FA, this ratio in a nitrogen matrix increases by a factor of approximately 2 compared to an argon matrix (see Table IV). It should also be remembered that the relative band intensities are already changed in an argon matrix. Wawrzyniak et al. ${ }^{35,36}$ reported a twofold increase of the $\mathrm{OH}$ stretching intensity for the hydrogen bonded FA $\cdots$ Ar complex. Combining these data, one may estimate that complexation with nitrogen leads to a four-fold increase of the $\mathrm{OH}$-stretching intensity, which is in reasonable agreement with our theoretical value for the strongest complexes (ca. 3.5). The results for AA follow the same general trends. However, for this compound the uncertainties in the determined experimental intensities are considerably larger due to band overlapping in the carbonyl stretching region making impossible the quantitative analysis. It is also probable that the rest of the matrix (in addition to the specific interaction) somewhat affects the vibrational intensities. Perhaps this leads to the large effect observed for the torsional intensities, which is not so well predicted by the model of specific interactions.

\section{Tunneling rates}

At the lowest temperatures, the cis- $\mathrm{HCOOH}$ decay rate in a nitrogen matrix is smaller by $\sim 55$ and 10000 times compared to argon and neon matrices, respectively. ${ }^{16,22}$ For $\mathrm{CH}_{3} \mathrm{COOH}$, the cis-to-trans conversion in a nitrogen matrix is slower by a factor of $\sim 600$ than in an argon matrix. ${ }^{18} \mathrm{At}$ ca. $8.5 \mathrm{~K}$, the cis- $\mathrm{HCOOH}$ decay in a nitrogen matrix is about five times slower than the decay in a xenon matrix ${ }^{16}$ and approximately 30 times slower than in a krypton matrix. For $\mathrm{CH}_{3} \mathrm{COOH}$, the tunneling rate is very similar in argon and krypton matrices, but it is five times faster in a xenon matrix. ${ }^{18}$ The tunneling rate of AA in a Xe matrix is ca. 3000 times greater than in a nitrogen matrix. Cis-to-trans conversion accelerates at elevated temperatures (Fig. 7), which suggests the influence of the matrix phonons to the tunneling process. ${ }^{16}$ The observed temperature dependence in a nitrogen matrix has a plateau for both acids where the tunneling rate remains practically constant. Such behavior demonstrates that up to a certain temperature (ca. $15 \mathrm{~K}$ in our case) the conversion process goes solely by tunneling.

We emphasize three experimental observations: (i) faster decay of cis-AA compared to cis-FA in all matrices; (ii) slower decay of the cis conformers in solid nitrogen than in rare-gas matrices; and (iii) closer decay rates of cis-AA and cis-FA in a nitrogen compared to argon matrix. The faster decay of cis-AA compared to $c i s$-FA can be explained by the lower cis-to-trans barrier for AA. The calculated cis-to-trans barriers are 4400 and $3921 \mathrm{~cm}^{-1}$ for AA and FA, respectively. ${ }^{8,9}$ Indeed, the barrier height is the most important factor controlling the tunneling rate. The different barriers also explain why the decay slows down in solid nitrogen

TABLE IV. Experimental relative intensities of FA and AA in nitrogen and argon (Ref. 14) matrices and the corresponding matrix shift $\left(\mathrm{cm}^{-1}\right)$.

\begin{tabular}{lcccccc}
\hline \hline & $\mathrm{N}_{2}$ matrix & Ar matrix & Shift & $\mathrm{N}_{2}$ matrix & Ar matrix & Shift \\
\hline & cis-FA & & \multicolumn{5}{c}{ trans-FA } \\
$\nu \mathrm{OH}$ & 0.83 & 0.45 & -19 & 0.57 & 0.32 & -21 \\
$\nu \mathrm{C}=\mathrm{O}$ & 1 & 1 & -5 & 1 & 1 & -6 \\
$\tau \mathrm{COH}$ & 0.45 & 0.28 & +32 & 0.21 & 0.50 & +37 \\
& $c i s-\mathrm{AA}$ & & & trans $-\mathrm{AA}^{\mathrm{a}}$ & & \\
$\nu \mathrm{OH}$ & 0.73 & 0.09 & -12 & 0.53 & 0.47 & $-12(-20)$ \\
$\nu \mathrm{C}=\mathrm{O}$ & 1 & 1 & -10 & 1 & 1 & $-1(-4)$ \\
$\tau \mathrm{COH}$ & 0.21 & 1.02 & +31 & 0.63 & 0.82 & $+18(+25)$ \\
\hline \hline
\end{tabular}

${ }^{\mathrm{a}}$ Data for site II; shifts for site I in parenthesis. 
compared to an Ar matrix. As discussed above, the spectroscopic data indicate the importance of the specific interaction between the hydrogen atom of the $\mathrm{OH}$ group and a nitrogen molecule. This interaction lowers the total energy of the system. On the other hand, this interaction is not efficient in the transition state for the case of a short tunneling time when the coordinates of the atoms are fixed (except the tunneling hydrogen). It follows that the cis-to-trans barrier becomes higher within the model of specific interactions approximately by the value of the dissociation energy of the corresponding hydrogen-bonded complex. This interaction is substantially weaker for an argon atom than for a nitrogen molecule. In agreement with the model of specific interactions, Marushkevich et $a{ }^{37}$ have found recently that the cis-FA $\cdots \mathrm{N}_{2}$ complex in an argon matrix has a lifetime of 48 min, i.e., 6.5 times longer compared to the cis-FA monomer. The same discussion is relevant to the third experimental observation that the decays of cis-AA and cis-FA in solid nitrogen become closer compared to an Ar matrix. Indeed, the hydrogen bonding to nitrogen is stronger for AA than for FA (by $0.7 \mathrm{~kJ} \mathrm{~mol}^{-1}$ ); hence the cis-to-trans barriers become similar for these molecules. It should be mentioned that additional factors exist which influence the tunneling rates. ${ }^{15,16,18,19}$

\section{CONCLUSION}

Formic and acetic acids have been studied in nitrogen matrices. The IR spectra of the cis and trans conformers of these species are assigned (Tables I and II). The higherenergy cis conformer of these molecules is produced by vibrational excitation of the more stable trans conformer. The decay of the cis forms is observed and explained by tunneling of hydrogen through the cis-to-trans torsional barrier, similarly to these species in rare-gas matrices. ${ }^{16,18}$ On the other hand, the tunneling for both molecules is considerably slower in a nitrogen matrix than in rare-gas matrices, for example, the cis-to-trans conversion of $\mathrm{HCOOH}$ slows down in a nitrogen matrix by four orders of magnitude compared to a neon matrix.

Both spectroscopic and tunneling data indicate that the $\mathrm{OH} \cdots \mathrm{N}_{2}$ specific interactions are important for both acids in a nitrogen matrix. Within the model of specific interactions, the tunneling barrier height should be higher in a nitrogen matrix than in an argon matrix. This conclusion is in agreement with the experimental observations on tunneling decay of AA and FA in a nitrogen matrix.

\section{ACKNOWLEDGMENTS}

These studies were partially funded by the Portuguese Science Foundation (Project No. FCOMP-01-0124-FEDER007458, cofunded by QREN-COMPETE-UE, and Grant No. SFRH/BD/29698/2006) and by the Academy of Finland through the Finnish Centre of Excellence in Computational Molecular Science. R.F. and S.L. acknowledge Milipeia Computer Centre (University of Coimbra), research project "Computação Avançada em Espectroscopia Molecular”. A.D. acknowledges a postdoctoral grant from the Faculty of Science, University of Helsinki (Project No. 7500101).

${ }^{1}$ B. Zuckerman, J. A. Ball, and C. A. Gottlieb, Astrophys. J. 163, L41 (1971).

${ }^{2}$ D. M. Mehringer, L. E. Snyder, Y. Miao, and F. J. Lovas, Astrophys. J. 480, L71 (1997).

${ }^{3}$ P. Ehrenfreund and S. B. Charnley, Annu. Rev. Astron. Astrophys. 38, 427 (2000).

${ }^{4}$ C. J. Bennett and R. I. Kaiser, Astrophys. J. 660, 1289 (2007).

${ }^{5}$ Z. Y. Meng, J. H. Seinfeld, and P. Saxena, Aerosol Sci. Technol. 23, 561 (1995).

${ }^{6}$ S. Yu, Atmos. Res. 53, 185 (2000).

${ }^{7}$ W. H. Hocking, Z. Naturforsch. A 31, 1113 (1976).

${ }^{8}$ M. L. Senent, Mol. Phys. 99, 1311 (2001).

${ }^{9}$ M. Pettersson, E. M. S. Maçôas, L. Khriachtchev, R. Fausto, and M. Räsänen, J. Am. Chem. Soc. 125, 4058 (2003).

${ }^{10}$ M. Pettersson, J. Lundell, L. Khriachtchev, and M. Räsänen, J. Am. Chem. Soc. 119, 11715 (1997).

${ }^{11}$ E. M. S. Maçôas, J. Lundell, M. Pettersson, L. Khriachtchev, R. Fausto, and M. Räsänen, J. Mol. Spectrosc. 219, 70 (2003).

${ }^{12}$ K. Marushkevich, L. Khriachtchev, J. Lundell, A. V. Domanskaya, and M. Räsänen, J. Mol. Spectrosc. 259, 105 (2010).

${ }^{13}$ E. M. S. Maçôas, L. Khriachtchev, M. Pettersson, R. Fausto, and M. Räsänen, J. Am. Chem. Soc. 125, 16188 (2003).

${ }^{14}$ E. M. S. Maçôas, L. Khriachtchev, R. Fausto, and M. Räsänen, J. Phys. Chem. A 108, 3380 (2004).

${ }^{15}$ L. Khriachtchev, J. Mol. Struct. 880, 14 (2008).

${ }^{16}$ M. Pettersson, E. M. S. Maçôas, L. Khriachtchev, J. Lundell, R. Fausto, and M. Räsänen, J. Chem. Phys. 117, 9095 (2002).

${ }^{17}$ E. M. S. Maçôas, L. Khriachtchev, M. Pettersson, R. Fausto, and M. Räsänen, Phys. Chem. Chem. Phys. 7, 743 (2005).

${ }^{18}$ E. M. S. Maçôas, L. Khriachtchev, M. Pettersson, R. Fausto, and M. Räsänen, J. Chem. Phys. 121, 1331 (2004).

${ }^{19}$ A. Domanskaya, K. Marushkevich, L. Khriachtchev, and M. Räsänen, J. Chem. Phys. 130, 154509 (2009).

${ }^{20}$ M. Gadermann, D. Vollmar, and R. Signorell, Phys. Chem. Chem. Phys. 9, 4535 (2007).

${ }^{21}$ P. Teragni, G. Masetti, and G. Zerbi, Chem. Phys. 28, 55 (1978).

${ }^{22}$ K. Marushkevich, L. Khriachtchev, and M. Räsänen, J. Chem. Phys. 126, 241102 (2007).

${ }^{23}$ T. P. Snow, Nature (London) 429, 615 (2004).

${ }^{24}$ GAMESS version R1 (24-Mar-2007); M. Schmidt, K. Baldridge, J. Boatz, S. Elbert, M. Gordon, J. Jensen, S. Koseki, N. Matsunaga, K. Nguyen, S. $\mathrm{Su}$, T. Windus, M. Dupuis, and J. Montgomery, J. Comput. Chem. 14, 1347 (1993).

${ }^{25}$ C. Møller and M. S. Plesset, Phys. Rev. 46, 618 (1934).

${ }^{26}$ A. D. McLean and G. S. Chandler, J. Chem. Phys. 72, 5639 (1980).

${ }^{27}$ M. J. Frisch, J. A. Pople, and J. S. Binkley, J. Chem. Phys. 80, 3265 (1984).

${ }^{28}$ J. Lundell, M. Räsänen, and Z. Latajka, Chem. Phys. 189, 245 (1994).

${ }^{29}$ J. Lundell, Chem. Phys. Lett. 266, 1 (1997).

${ }^{30}$ See supplementary material at http://dx.doi.org/10.1063/1.3484943 for Figs. S1-S4, showing the calculated structures of the $\mathrm{N}_{2}$ complexes of $\mathrm{cis}$ and trans FA and AA and for Table S-I, showing the calculated $\nu \mathrm{OH}$, $\nu \mathrm{C}=\mathrm{O}$, and $\tau \mathrm{COH}$ frequencies and IR intensities for monomeric cis and trans forms of FA and AA and their complexes with $\mathrm{N}_{2}$.

${ }^{31}$ R. Fausto, L. A. E. Batista de Carvalho, J. J. C. Teixeira-Dias, and M. N. Ramos, J. Chem. Soc., Faraday Trans. 2 85, 1945 (1989).

${ }^{32}$ M. Rozenberg, G. Shoham, I. D. Reva, and R. Fausto, Phys. Chem. Chem. Phys. 7, 2376 (2005).

${ }^{33}$ M. Rozenberg, G. Shoham, I. D. Reva, and R. Fausto, Spectrochim. Acta, Part A 60, 463 (2004).

${ }^{34}$ R. Fausto, J. Mol. Struct.: THEOCHEM 315, 123 (1994).

${ }^{35}$ P. K. Wawrzyniak, J. Panek, J. Lundell, and Z. Latajka, J. Mol. Model. 11, 351 (2005)

${ }^{36}$ P. K. Wawrzyniak, J. Panek, Z. Latajka, and J. Lundell, J. Mol. Struct. 704, 297 (2004).

${ }^{37}$ K. Marushkevich, M. Räsänen, and L. Khriachtchev, J. Phys. Chem. A 114, 10584 (2010). 
The Journal of Chemical Physics is copyrighted by the American Institute of Physics (AIP). Redistribution of journal material is subject to the AIP online journal license and/or AIP copyright. For more information, see http://ojps.aip.org/jcpo/jcper/jsp 